\title{
Environmental Impact Assessment of Multi-Pollutant Emission in Cotton Fabric Production
}

\author{
Ke Wang ${ }^{1,2}$, Hong Liu ${ }^{2,3}$, Xiaopeng Wang 4, 5, Laili Wang, 2, 4* \\ ${ }^{1}$ School of Fashion Design \& Engineering, Zhejiang Sci-Tech University, Hangzhou, Zhejiang 310018, China \\ ${ }^{2}$ Key Laboratory of Silk Culture Heritage and Products Design Digital Technology, Ministry of Culture and Tourism, \\ Hangzhou 310018, China \\ ${ }^{3}$ Qingdao University, Collage of Textile \& Clothing, Qingdao 266071, China \\ ${ }^{4}$ Zhejiang Ecological Civilization Research Center, Hangzhou 310018, China \\ ${ }^{5}$ Institute of Science and Technology, Zhejiang Sci-Tech University, Hangzhou 310018, China
}

Received: 27 November 2020

Accepted: 10 February 2021

\begin{abstract}
The textile industry continuously attracts extensive attention because of the excessive water consumption and high pollutants emissions. Water footprint as an analytical tool is widely used in water resources management in recent years. However, the water footprint method is not adequate in comprehensive assessment of water pollution impact from the perspective of water quality change in different duration of time. The total environmental impact score (TEIS) methodology can evaluate the environmental impact of each kind of water pollutant, and taking into account the actual wastewater volume, which enables it to accurately and comprehensively identify the environmental impact of water pollutants. In this study, the production of cotton fabric was chosen as an example to evaluate the impact of wastewater discharge with TEIS method. The results showed that the environmental impact caused by wastewater discharged in batch dyeing was the greatest, followed by pretreatment and after-finishing. This was mainly because large amounts of dyes were used in the batch dyeing stage and generated many wastewater pollutants. Phosphorus caused the most severe impact, accounting for $41.5 \%$ of the total environmental impact.
\end{abstract}

Keywords: cotton fabric, total environmental impact score, multi-pollutants, water quality, environmental impact

*e-mail: wangll@zstu.edu.cn 


\section{Introduction}

Global demand for textiles is growing concomitantly, and the world textile consumption expected to quadruple by 2050 [1]. As the world's largest producers, exporters, and consumers of textiles, China's textile production has boosted the domestic and even the world economy at the cost of serious environmental problems, including of water resources shortage and water pollution. The wastewater discharged from the Chinese textile industry took 13 percent of the all 41 manufacturing industries, and it ranked $2^{\text {nd }}$ in ammonia nitrogen $\left(\mathrm{NH}_{3}-\mathrm{N}\right)$ discharge and chemical oxygen demand (COD) discharge in 2015, respectively [2]. As an indispensable material, cotton is one of the most widely used fibers in world's textile and garment production [3]. Cotton products are popular because of their characteristics of high moisture absorption, softness and low price [4]. However, large amount of wastewater and the pollutants emitted from cotton textile production cannot be ignored. It takes 8.5 tons of water to produce 1 kilogram of cotton fabric [3], and the use of dyes, additives, finishing agents, and other chemicals generate a large amount of wastewater pollutants with complex components in the dyeing and finishing phase, such as COD, ammonia nitrogen, and sulfides $[5,6]$. With the aim of alleviating the water scarcity and pollution problems, the clean production of textile products and garments has been proposed as one of the key development directions in the $21^{\text {st }}$ century. It aims to strengthen the management of freshwater consumption and wastewater discharge of the textile industry. For cotton textile production, a comprehensive and accurate analysis of the freshwater consumption and wastewater pollutants discharge and their impacts on the water environment in each production process is crucial to provide a theoretical basis for water management and achieve clean production.

In terms of environmental impact, the carbon footprint of cotton textile production has been discussed and explored [7-9]. Moreover, the water footprint (WF) is a comprehensive indicator used to assess the water resources occupied by human activities. WF was first proposed including the blue WF, green WF and grey WF [10], which were widely used to evaluate the freshwater consumption and water pollution impact of textile production. For example, Wang et al. and Gao et al. calculated the direct blue WF and grey WF of China's textile industry, respectively $[11,12]$. Wang et al. calculated the WFs of knitted fabrics and the results showed that large amounts of high-concentration pollutants were emitted during the dyeing and printing stage [13]. Li et al. argued that technology was the most important factor that inhibits the WF of Chinese textile industry [14]. For cotton textile production, Chapagain and $\mathrm{Li}$ analyzed and discussed problems in the accounting and evaluation of the WF of textile products $[15,16]$. Yan et al. used the industrial WF methodology to calculate and evaluate four typical cotton textiles, and the results showed that the blue WF was larger than the grey WF [17].

From the research presented above, the conclusion can be drawn that the cotton textile production, especially the dyeing stage, caused the impact on water resources cannot be ignored. Grey WF (GWF) was proposed as an indicator of the degree of freshwater pollution. However, GWF method has several shortcomings. Firstly, GWF only considers the volume of water required to dilute characteristic pollutants, the cumulative effect of multiple pollutants in wastewater is ignored [18, 19]. Secondly, wastewater causes the water quality deterioration by discharged into natural water, but the GWF focuses on water quantity and without considering the change of the quality of receiving water [20-22]. The total environmental impact score (TEIS) takes into consideration of the amount of wastewater discharged and the concentration of a variety of pollutants, and uses water quality as an important factor in the evaluation of environmental impacts on water resource [23]. TEIS method overcomes previously described limitations of the GWF method and can be used to evaluate the environmental impact on water resources caused by industrial production of textiles.

This study used the TEIS method to achieve the following aims: (1) quantify the TEIS of typical types of cotton fabric in terms of the main production processes and major pollutants; and (2) conduct a comprehensive water environmental impact assessment by involving the wastewater quantity and multi-pollutant factors. It will fill the gap of WF assessment of cotton textiles and is meaningful for cotton textiles producers to accurately and effectively alleviate the environmental impacts caused by freshwater consumption and waste water discharge.

\section{Material and Methods}

The study conducted a water environmental impact assessment of multi-pollutant wastewater discharge, using the concentrations of water pollutants and the volume of wastewater to calculate the TEIS of each production process. The accounting functional unit for the TEIS analysis was $1,000 \mathrm{~kg}$ of cotton fabric. The input of raw materials and the pollutants discharged were based on the production of $1,000 \mathrm{~kg}$ of the cotton fabric.

\section{System Boundary Description}

In the cotton fabric production, dyeing and finishing was the stage in which the largest amount of wastewater pollutants was discharged. This stage included pretreatment, batch dyeing, and after-finishing. The pollutants included biochemical oxygen demand (BOD), COD, nitrogen $(\mathrm{N})$, phosphorus $(\mathrm{P})$ and sulfides (Fig. 1). Heavy metal pollutants such as chromium, lead, and 


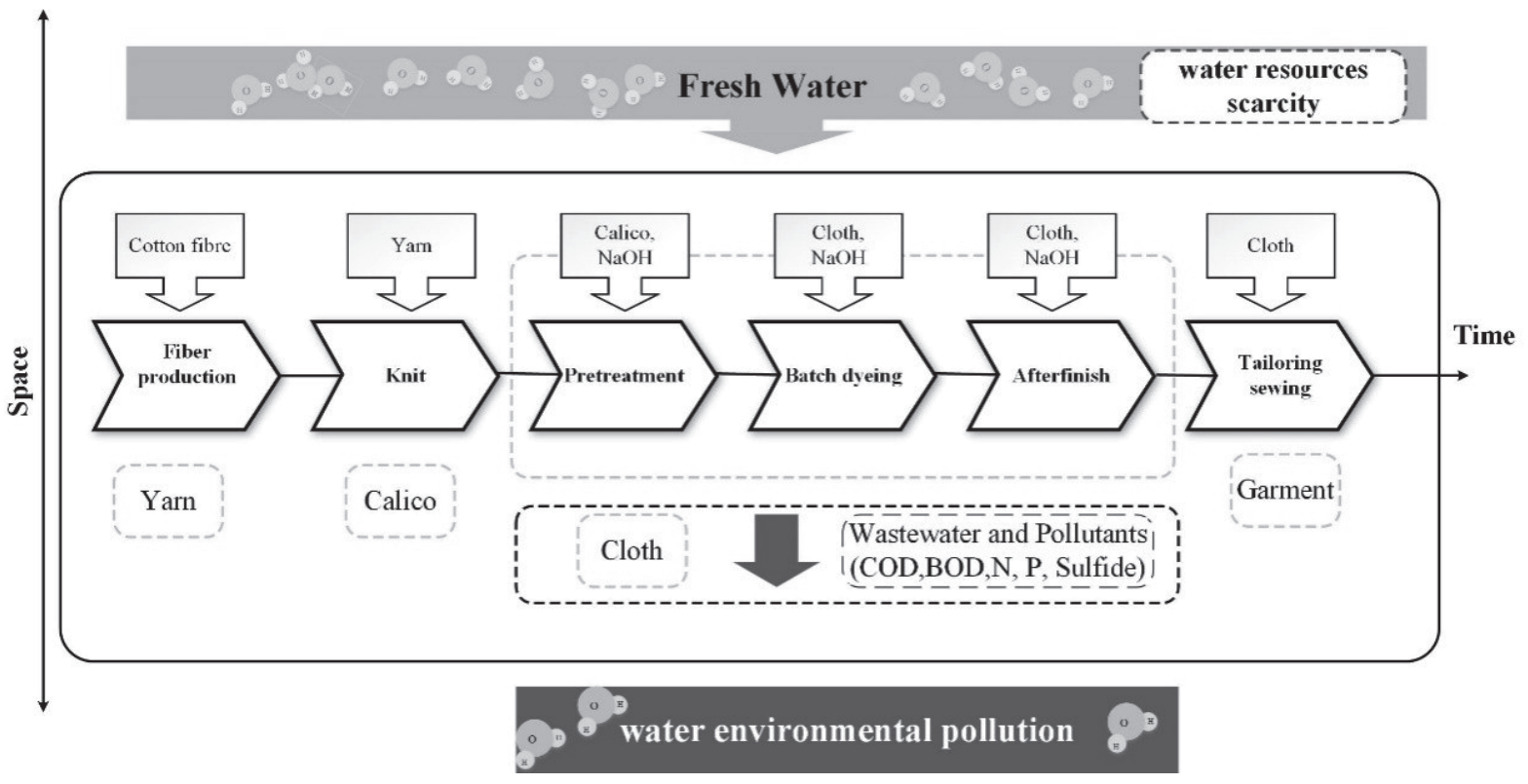

Fig. 1. System boundary of TEIS calculation for cotton fabric.

zinc were not included in the evaluation due to their low quantities.

\section{TEIS Calculation}

As an environmental impact assessment tool, TEIS combines wastewater discharge and water quality factors to quantify the environmental impact of multiple wastewater pollutants [23]. The TEIS calculation method can be expressed as follows (Eq. 1):

$$
T E I S=\frac{q}{q_{0}} \cdot \sum_{i=1}^{n}\left(w_{i} \frac{c_{i}}{c_{i 0}}\right)
$$

...where $q_{0}$ and $q$ are the benchmark discharge and actual discharge of the production process, respectively; $C_{i 0}$ and $C_{i}$ are the permissible and actual discharge concentration of pollutant $i ; n$ is the amount of pollutant in the wastewater; and $w_{i}$ denotes the weight of pollutant $i$. As the weight of each pollutant is difficult to determine, this study used the equivalent weight 1 , which is widely used in air quality assessment [23].

\section{GWF Calculation}

The GWF was defined as the maximum volume of water required to assimilate each pollutant load to the corresponding water quality standards based on the concentration of natural water bodies and the concentration of the existing ambient water quality standards [24]. The GWF of each production process can be calculated as follows (Eq. 2):

$$
W F_{\text {grey }}=\max \left(\frac{L_{i}}{C_{\text {max }}-C_{\text {nat }}}\right)
$$

where $W F_{\text {grey }}\left(\mathrm{m}^{3}\right)$ is GWF; $L_{i}(\mathrm{mg})$ is the quality of pollutant $i$ in the discharged wastewater; $C_{\max }(\mathrm{mg} / \mathrm{L})$ is the concentration of pollutant $i$ in the water-quality standards; $C_{\text {nat }}(\mathrm{mg} / \mathrm{L})$ is the concentration of pollutant $i$ in natural water.

\section{Data Collection}

The data regarding wastewater and pollutant discharge in each process of cotton fabric production were derived from Daystar's study of the life-cycle assessment of cotton textiles [25]. The concentration limits of the water pollutants were all taken from a standard "GB 4287-2012 Discharge standard of water pollutant for dyeing and finishing of textile industry".

In this research, the environmental water quality standard used was "GB 3838-2002 Environmental quality standards for surface water", class III, as recommended by Hoekstra, which pertains to water suitable for centralized drinking water [26]. This standard was more stringent than the pollutant discharge standard mentioned above and more clearly showed the characteristics of the water environment. The concentration of pollutant $i$ in natural water $\left(\mathrm{C}_{\text {nat }}\right)$ hypothesis equals to zero [27].

\section{Results and Discussion}

\section{Results of TEIS}

The TEISs of cotton fabric (per functional unit) production processes were shown in Fig. 2. It can be seen that the total TEIS of per functional unit was 6.3. Batch dyeing had the biggest contribution (i.e., 


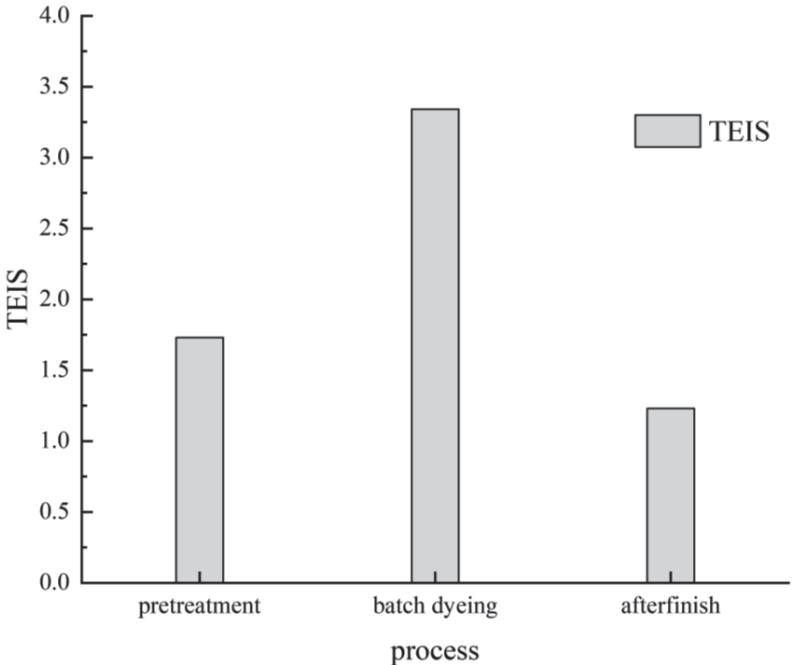

Fig. 2. The TEISs of production processes.

$53.01 \%$ ) to the total TEIS, followed by pretreatment (i.e., 27.46\%) and after-finishing (i.e., 19.53\%). This was mainly because batch dyeing process discharged the most wastewater, which was 2.06 times and 4.65 times of pretreatment and after-finishing, respectively.

From the perspective of high added value and technical complexity, the dyeing stage is one of the most important processes in textile production [28]. Nearly $80 \%$ of cotton fabric dyeing rely on the continuous padding process in the Chinese industry [29]. And wet processing is an essential operation in the continuous padding process, which produces a large amount of wastewater and pollutants [30]. This was the mainly reason why TEIS of batch dyeing was the largest. The pretreatment stage of cotton fabrics mainly includes desizing, scouring, oxygen bleaching processes. Using of desizing enzymes and scouring agents produces more wastewater pollutants than the after-finishing process, so the TEIS in the pretreatment stage was larger than the after-finishing process [31-32]

\section{Results of TEIS of Each Production Process and Pollutant}

The TEISs of wastewater pollutants (per functional unit) discharged in production processes were calculated according to Eq. (2) and showed in Fig. 3. The TEISs of pollutants in the batch dyeing process were in the following order: $\mathrm{P}>\mathrm{COD}>\mathrm{BOD}>\mathrm{N}>$ sulfide. It was the same as the order of TEISs of pollutants discharged in the pretreatment process. As to after-finishing process, TEIS of $\mathrm{P}$ was also the largest and followed by sulfide, N, COD and BOD.

Due to the wastewater discharge from cotton fabric production was far less than the benchmark discharge, the TEIS value of each pollutant was mainly determined by the ratio between the concentration of pollutant discharged and the baseline discharge limitation. The content of $\mathrm{N}$ and $\mathrm{P}$ in cotton fabric dyeing wastewater

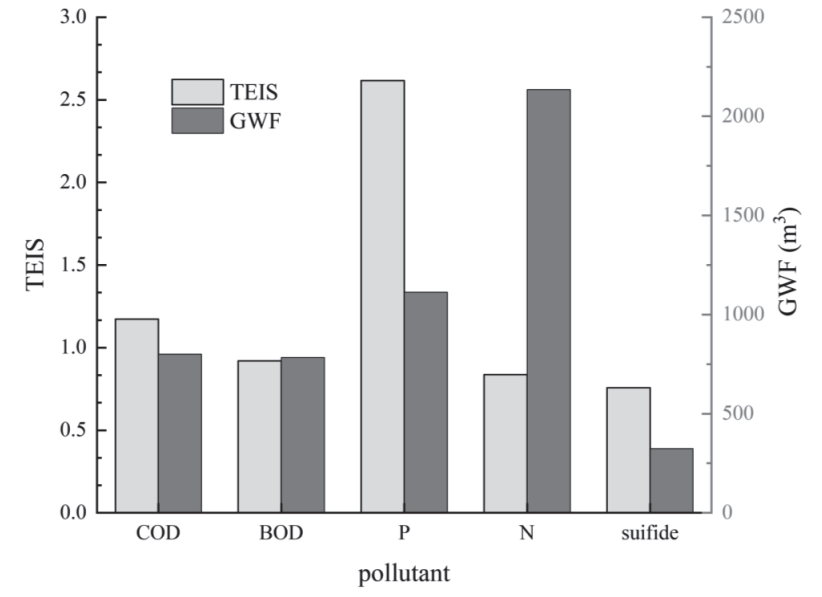

Fig. 3. The TEISs of wastewater pollutants.

was relatively low, but $\mathrm{P}$ contributed the most to the total TEIS, accounting for 41.52 percent, which was 2.23 times more than COD. The main reason was that the concentration of $\mathrm{P}$ discharged exceeded the discharge limitation greatly in the three production processes. The discharge of $\mathrm{P}$ from the dyeing and finishing process was derived from phosphorus-containing additives added in the process of pickling and neutralization and the hydrolysis of dye at high temperature [33]. COD and BOD were the main components of dyeing and finishing wastewater, the TEIS ranked the third and fourth place with value of 1.172 and 0.919 , respectively. They were mainly derived from the chemical auxiliaries utilized during procedures such as desizing and batch dyeing and these chemical auxiliaries basically remain in the wastewater [34].

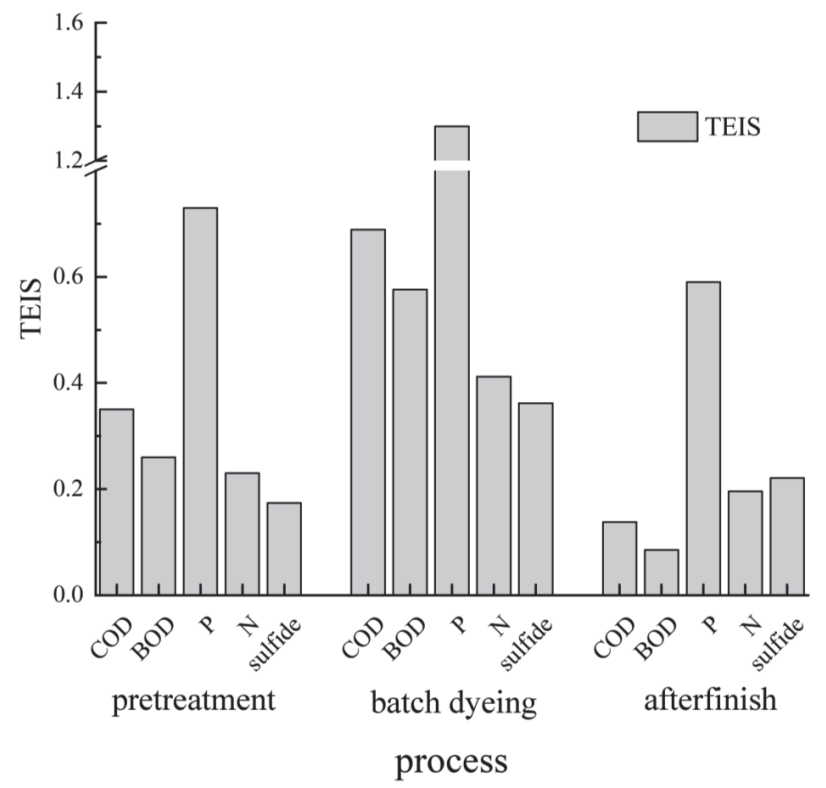

Fig. 4. The TEIS and GWF of each pollutant. 


\section{Results of Pollutant TEIS and GWF}

Fig. 4 showed the TEIS and the GWF of the pollutants (per functional unit). The orders of the environmental impact of the pollutants were different for the two evaluation methods. $\mathrm{N}$ pollutant caused the most severe impact on water resource according to GWF method, and followed by P, COD, BOD and sulfide. The total TEIS results of the five wastewater pollutants were in the following descending order: $\mathrm{P}>\mathrm{COD}>\mathrm{BOD}>\mathrm{N}>$ sulfide.

GWF method did not consider the actual wastewater volumes and changes in water quality. It assessed the environmental impact from the quantitative aspect. In the dyeing and finishing stage, GWF represented the volume of fresh water, which was required to dilute the concentration of $\mathrm{N}$ based on the existing ambient water quality standards. It ignored other pollutants in the wastewater as $\mathrm{N}$ was the typical pollutants that caused the largest GWF. The TEIS represented the cumulative effect of each pollutant. Compared with the GWF method, the TEIS method provided a more accurate method to identify the environmental impact of different pollutants and processes by considering multiple pollutants and the amount of wastewater in the cotton fabric production.

\section{Conclusion}

Water pollution of textile industry is progressively perceived as a socio-environmental threat that could impair the ecosystems. In this paper, two models were employed and compared for assessing the water environmental impact of the cotton fabric production. Compared with GWF method, TEIS method took the volume of wastewater and the concentration of multiple pollutants into account. This overcame the shortcoming that GWF was mainly influenced by the concentration of the typical pollutant.

This case study makes the public detecting that the wastewater and pollutants discharge from dyeing and finishing for cotton fabric production are substantial. The results have shown that the TEIS of the batch dyeing process accounted for the largest proportion of the total TEIS. The water environmental impact of the batch dyeing mainly originated from the phosphorus discharge. Among all the pollutants, phosphorus was the key contributor to GWF and TEIS in each process as its discharged concentration was greatly exceeded the emission limits. In order to reduce the water environmental impact of the cotton fabric production, measures should be considered on further intensifying phosphorus removal from wastewater.

This paper could support future studies in choosing suitable approaches to reduce the water environmental impact in cotton fabric production. However, an equivalent weighting coefficient 1 was assigned to each pollutant when calculated the water environmental impact in this study. For further studies, the priority weight of different pollutants should be identified to support decision-making in environmental impact assessment.

\section{Acknowledgements}

The authors are grateful to the Zhejiang Provincial Natural Science Foundation (LY20G030001), the Key Laboratory of Silk Culture Heritage and Products Design Digital Technology, Ministry of Culture and Tourism, P.R.China (2020WLB04), General Scientific Research Project of Zhejiang Provincial Education Department (201930404023) for providing funding supports to this research and the Fundamental Research Funs of Zhejiang Sci-Tech University (2021Y008).

\section{Conflict of Interest}

The authors declare no conflict of interest.

\section{References}

1. ALKHAGEN M., SAMUELSSON A., ALDAEUS F., GIMAKER M., COSTMARK E., SWERIN. Roadmap 2015 to 2025: Textile Materials from Cellulose Wood. Research Insititutes of Sweden, 2015.

2. Ministry of Environmental Protection PRC. China Environmental Statistics Annual Report 2016. China Environmental Science Press, 2016.

3. ESTEVE-TURRILLAS F.A., GUARDIA M. Environmental impact of Recover cotton in textile industry. Resources, Conservation and Recycling, 116, 107, 2017.

4. ZHANG Y., LIU X., XIAO R.F. Life cycle assessment of cotton T-shirts in China. International Journal of Life Cycle Assessment, 20(7), 994, 2015.

5. WANG Y.Q., WU J.L. Discussion of new clean technology in textile printing and dyeing industry. Heibei Journal of Industrial Science and Technology, 28 (6), 397, 2011.

6. CHEN L.H. Carbon Emissions Analysis of Clothing Materials Production. Cotton Textile Technology, 42 (8), 79, 2014.

7. MUTHU S.S., LI Y., HU J.Y., ZE, L. Carbon footprint reduction in the textile process chain: Recycling of textile materials. Fibers and Polymers, 13 (8), 1065, 2012.

8. WANG C.Y., WANG L.H., LIU X.L., DU C., DING D., JIA J., YAN Y., WU G. Carbon footprint of textile throughout its life cycle: a case study of Chinese cotton shirts. Journal of Cleaner Production, 108, 464, 2015.

9. GAO X.L., LU J.Q., ZHU J.Z., WANG D.T. Calculation and analysis on overall energy consumption and carbon footprint of cotton fabric product. Shanghai Textile Science \&Technology, 44 (10), 53, 2016.

10. LI Y., TAN Y.X., WANG L.L., SHEN M.H. Decoupling Water Consumption and Environmental Impact on Textile Industry by using Water Footprint Method: A Case Study in China. Water, 9 (2), 124, 2017.

11. WANG L.L., DING X.M., WU X.Y., YU J. Textiles industrial water footprint: methodology and study. Journal of Scientific \& Industrial Research, 72, 710, 2013. 
12. GAO Y., MA G.Q., LI Z.S. Evaluation of water resources utilization based on water footprint theory -taking textile industry in China for example. Resource Development \& Market, 36 (3), 241, 2020.

13. WANG L.L., WU X.Y., DING X.M., WANG L.H., Yu, J.M. Case study on industrial carbon footprint and industrial water footprint of cotton knits. Dyeing and Finishing, 38 (7), 43, 2012.

14. LI Y., LU L.Y., TAN Y.X., WANG L.L., SHEN M.H. Decoupling water consumption and environmental impact on textile industry by using water footprint method: a case study in China. Water. 9 (2), 124, 2017.

15. CHAPAGAIN A.K., HOEKSTRA A.Y., SAVENIJE H.H., GAUTAM R. The water footprint of cotton consumption: an assessment of the impact of worldwide consumption of cotton products on the water resources in the cotton producing countries. Ecol. Econ, 60 (1), 186, 2006.

16. LI J.H., DING X.M., WU X.Y. Study on Accounting and Assessment of Cotton Carbon \& Water Footprint. Cotton Textile Technology, 47 (10), 73, 2019.

17. YAN Y., JIA G.X., SHAN P., WU G. Water environmental impact assessment of urban development based on water degradation footprint: a case study of Beijing. Acta Scientiae Circumstantiae, 37 (2), 779, 2017.

18. LIU W.F., ANTONEALlI M., LIU X.C., YANG H. Towards improvement of grey water footprint assessment: With an illustration for global maize cultivation. Journal of Cleaner Production, 147, 1, 2017.

19. YU C.X., YIN X.N., LI H., YANG Z.F. A hybrid waterquality-index and grey water footprint assessment approach for comprehensively evaluating water resources utilization considering multiple pollutants. Journal of Cleaner Production, 248, 119225. 2020.

20. GU Y.F., LI Y., WANG H.T., LI, F. Grey Water Footprint: Taking Quality, Quantity, and Time Effect into Consideration. Water Resour Manage. 28, 3871, 2014.

21. ZHAO Z., LIU G.J., SAVENIJE H.H.G. A simple approach to assess water scarcity integrating water quantity and quality. Ecological Indicators, 34, 441, 2013.

22. XU L.L., WU X.Y., CHEN L.Z., DING X.M. Selection of relevant parameters in calculation of grey water footprint of textiles and apparel. Dyeing and Finishing, 41(13), 38, 2015.
23. SUN W.Q., XU X.D., LV Z.Q., MAO H.J., WU J.Z. Environmental impact assessment of wastewater discharge with multi-pollutants from iron and steel industry. Journal of Environmental Management, 245, 210, 2019.

24. FRANKE N.A., BOYACIOGLU H., HOEKSTRA A.Y. Grey water footprint accounting: Tier 1 supporting guidelines. UNESCO-IHE Institute for water education, 2013.

25. DASYTAR J. LCA update of cotton fiber and fiber and fabric life cycle inventory. Cary: Cotton Incorporated, 2017.

26. WANG L.L., WU X.Y., DING X.M., LI Y. Calculation and assessment of industrial water footprint of textiles and apparel. Journal of Textile Research, 38(9), 162, 2017.

27. WANG L.L., DING X.M., WU X.Y. Careful considerations when reporting and evaluating the grey water footprint of products. Ecological Indicators, 41, 131, 2014.

28. 28. JIANG W.L., YUAN Z.W., BI J., SUN L. (2010) Conserving water by optimizing production schedules in the dyeing industry. Journal of Cleaner Production, 18 (16-17), 1696, 2010.

29. Global Textiles. China textile news Chinamade continuously plays a key role. 2009. http://www.tnc.com. cn/news/detail/1/2/d123587.html. Accessed 7 July 2011

30. IBRAHIM N.A., MONEIM N.M.A., HALIM E.S.A., HOSNI M.M. Pollution prevention of cotton-cone reactive dyeing. Journal of Cleaner Production, 16 (12), 1321, 2008.

31. YUAN Z.W., ZHU Y.N., SHI J.K., LIU X., HUANG L. Life-cycle assessment of continuous pad-dyeing technology for cotton fabrics. The International Journal of Life Cycle Assessment, 18, 659, 2013.

32. LIU T.D., XU C.R., LI Q.H., XIONG R.G., ZHOU W.B. Wet processing of cotton/Yilon blended fabric. Dyeing and Finishing, 44 (13), 32, 2018.

33. GONG X.M., LIU J.M., ZHU S., LIU R. Calculation and assessment of water footprint in wet processing of cotton towels. Dyeing and Finishing, 2021.

34. XI D.L., MA C.Y. Classification, composition and properties of dyeing effluents. Dyeing and Finishing, 36 (14), 51, 2010. 